The final published version of this article can be found at http://dx.doi.org/10.1016/j.tetlet.2009.03.224. 


\section{Intramolecular amidocyclopropanation reactions using diethoxymethyl- functionalised lactams as organozinc carbenoid precursors}

Laure Jerome, Tom D. Sheppard, Abil E. Aliev, William B. Motherwell*

Department of Chemistry, Christopher Ingold Laboratories, University College London, 20 Gordon Street, London, UK WC1H 0AJ Fax: $+44(20) 76797524$.

E-mail: w.b.motherwell@ucl.ac.uk.

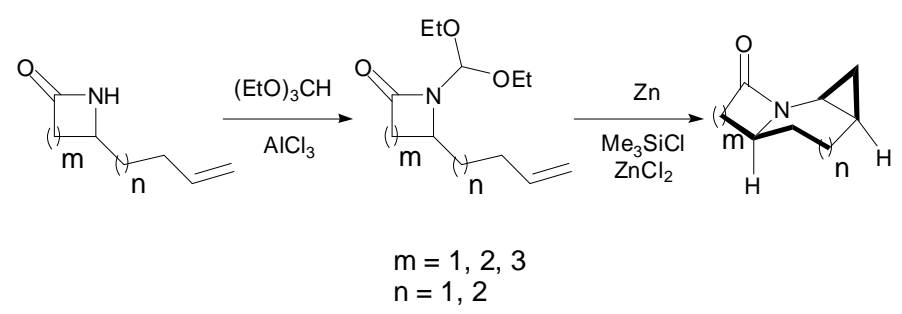

Intramolecular amidocyclopropanation reactions of diethoxymethyllactams containing a pendant alkene were examined using zinc/TMSCl. With a range of 4-6 membered lactams, bicyclic amidocyclopropanes were obtained with very high diastereoselectivity with a preference for the formation of the more hindered endo-cyclopropane. 


\section{Intramolecular amidocyclopropanation reactions using diethoxymethyl- functionalised lactams as organozinc carbenoid precursors}

Laure Jerome, Tom D. Sheppard, Abil E. Aliev, William B. Motherwell*

Department of Chemistry, Christopher Ingold Laboratories, University College London, 20 Gordon Street, London, UK WC1H 0AJ

Fax: $+44(20) 76797524$.

E-mail: w.b.motherwell@ucl.ac.uk.

Received: The date will be inserted once the manuscript is accepted..

Keywords: lactams, carbenoids, cyclopropanes, zinc, alkenes.

The aminocyclopropyl unit is present in a considerable number of biologically active natural products and pharmaceuticals. ${ }^{1}$ In structural terms, the rigidity of this small ring provides an excellent molecular scaffold for precise location of functional groups within a more complex system. In contrast to traditional carbene or carbenoid methods for aminocyclopropane synthesis such as Simmons-Smith addition to an enamine or enamide derivative ${ }^{2}$ or those which require subsequent functional group manipulation, as in the Curtius rearrangement of cyclopropyl carboxylic acids, ${ }^{3}$ our current strategy involves direct cyclopropanation of simple alkenes using heteroatom-functionalised organozinc carbenoids. $^{4-6}$ Thus, as encapsulated in Scheme 1, an organozinc carbenoid $\mathbf{4}$ can be generated directly and efficiently from a diethoxymethylamide 1 in the presence of metallic zinc, chlorotrimethylsilane and a Lewis acid. A plausible mechanism involves activation of an ethoxy group of the orthoamide by the Lewis Acid and chlorotrimethylsilane, thus generating an intermediate 2, which, on subsequent delivery of two electrons from zinc leads to the organozinc carbenoid 4 which can then cyclopropanate an alkene (Scheme 1). 


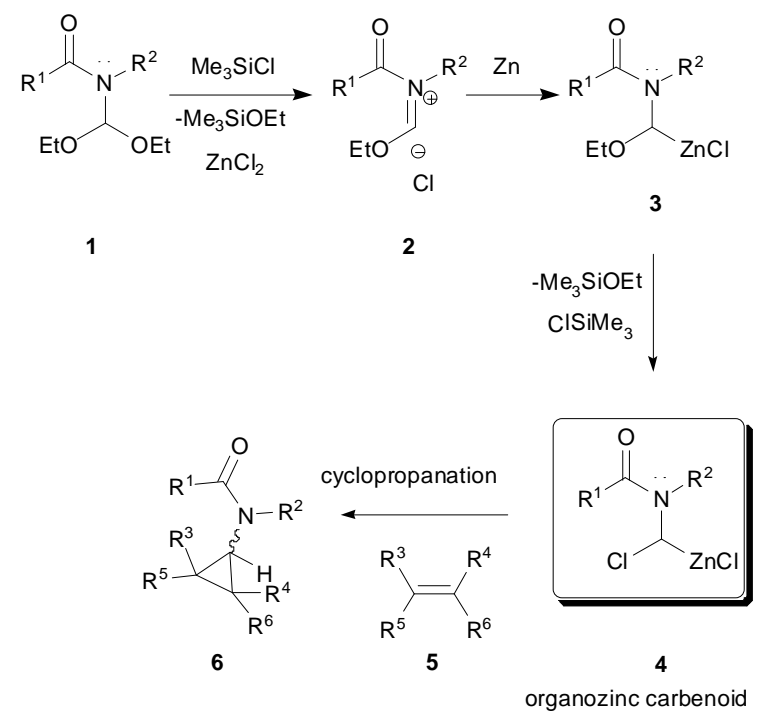

\section{Scheme 1}

We have recently reported on the use of this protocol for the synthesis of a variety of structurally interesting functionalised amidocyclopropanes ${ }^{6}$ and, in view of the significant number of antiviral, ${ }^{7}$ antibacterial $^{8}$ and antitumor compounds ${ }^{9}$ which contain an aminocyclopropyl ring within a polycyclic framework, it was of particular interest to investigate the potential of the intramolecular variant of our organozinc carbenoid reaction on suitably substituted lactams 7-12 (Scheme 2).

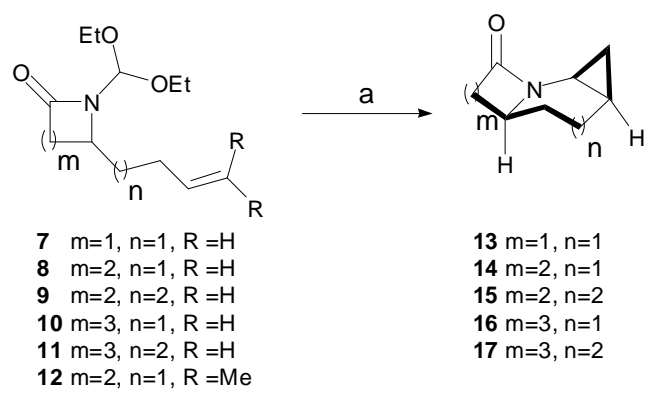

Scheme 2 Reagents and conditions a) $\mathrm{Zn}$ source, $\mathrm{Me}_{3} \mathrm{SiCl}, \mathrm{ZnCl}_{2}, \mathrm{Et}_{2} \mathrm{O}, 44{ }^{\circ} \mathrm{C}$.

In recent times, a variety of approaches for the preparation of polycyclic aminocyclopropranes via intramolecular reactions have been reported, including elegant variants of the Kulinkovich ${ }^{10}$ reaction developed by de Meijere $^{11}$ using Ti(II)-mediated coupling of tethered $N, N$-dialkylamides, ${ }^{12}$ and transition metal-mediated cyclopropanation of enamides with diazoesters. ${ }^{13}$ It should be noted however, as highlighted in Scheme 2, that the tricyclic products produced in the present method also contain a lactam functionality useful for further elaboration, and that, in contrast to the titaniummediated intramolecular cyclopropanation of $\omega$-vinylimides, ${ }^{12 a}$ a linearly-fused tricyclic system is obtained.

The lactams 22-26 were prepared simply from cyclic imides 19 and 20 by a one-pot sequence involving reaction with an excess of the appropriate unsaturated Grignard reagent, followed by 
reduction, ${ }^{14}$ whilst lactam 21 was prepared by [2+2] cycloaddition of 1,5-hexadiene 18 and chlorosulfonyl isocyanate (Scheme 3). ${ }^{15}$ The lactams were then heated in triethyl orthoformate at 160 ${ }^{\circ} \mathrm{C}$ in the presence of a catalytic amount of aluminium chloride to give the diethoxymethyllactams 712. ${ }^{16}$ The yields for these steps are given in Table 1.

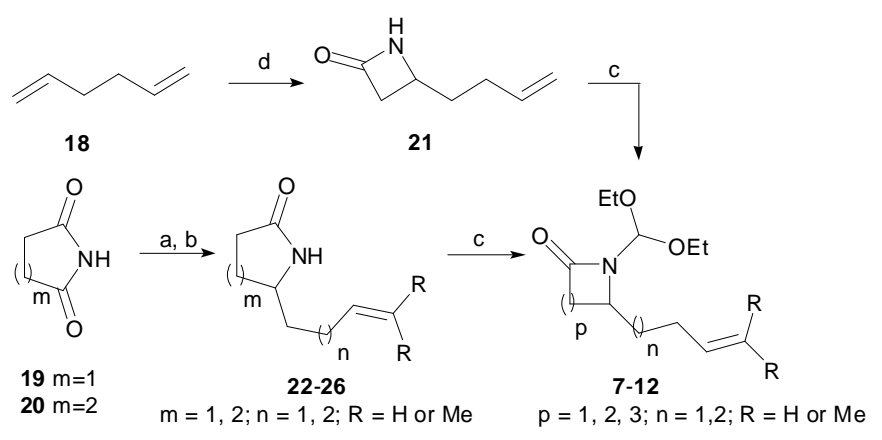

Scheme 3 Reagents and conditions: a) $\mathrm{R}_{2} \mathrm{C}=\mathrm{CH}\left(\mathrm{CH}_{2}\right)_{\mathrm{n}} \mathrm{CH}_{2} \mathrm{MgBr}$, THF; b) $\mathrm{NaBH}_{3} \mathrm{CN}$, AcOH, THF, then $5 \%$ aq. $\mathrm{NaOH}$; c) $\mathrm{AlCl}_{3}, \mathrm{CH}(\mathrm{OEt})_{3}, 160{ }^{\circ} \mathrm{C}$; d) $\mathrm{ClSO}_{2} \mathrm{NCO}, \mathrm{CH}_{2} \mathrm{Cl}_{2}$ r.t., 7 days, then $\mathrm{Na}_{2} \mathrm{SO}_{3}$, $\mathrm{KOH}, \mathrm{H}_{2} \mathrm{O}$.

With the carbenoid precursors 7-12 in hand, the intramolecular cyclopropanation was readily performed using a zinc source in the presence of trimethylsilyl chloride and zinc chloride in refluxing diethyl ether, to give the corresponding cyclopropanes in moderate yields (Scheme 2, Table 1). Trace amounts of the starting lactam derived from hydrolysis of the orthoamide were also noted.

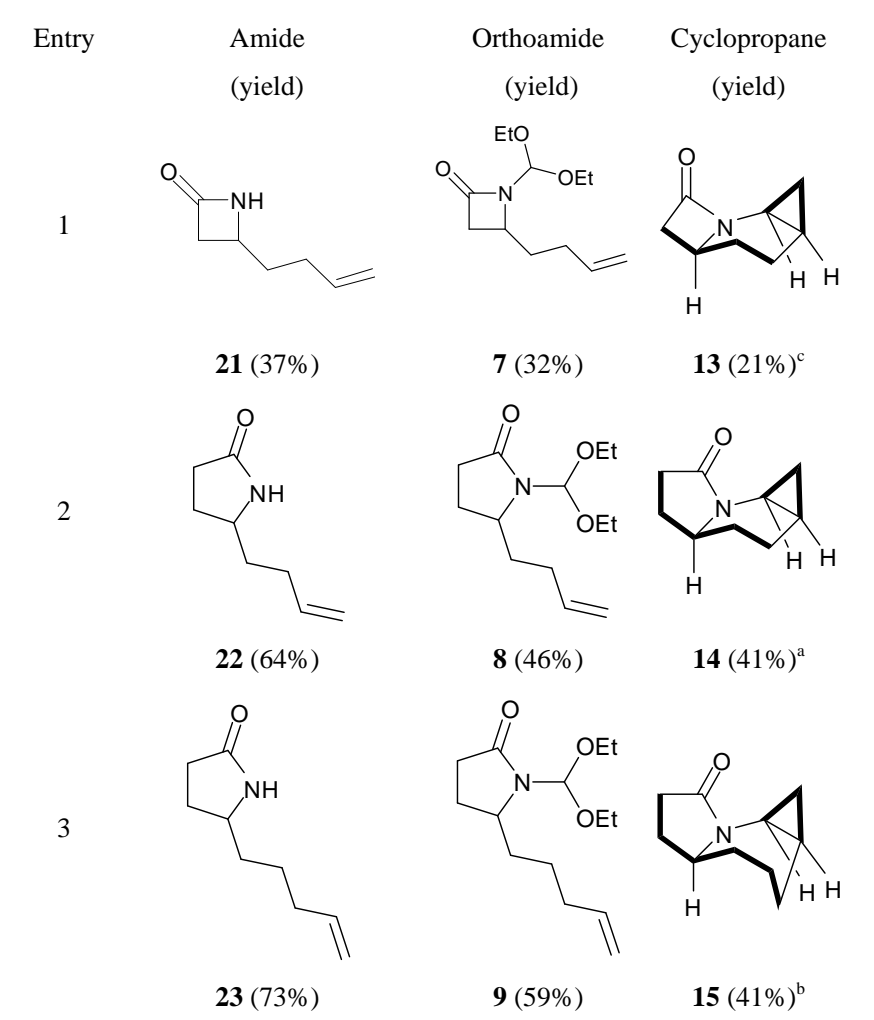


4<smiles>C=CCCC1CCCC(=O)N1</smiles>

$24(66 \%)$

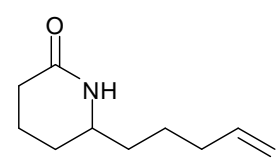

$25(68 \%)$

6

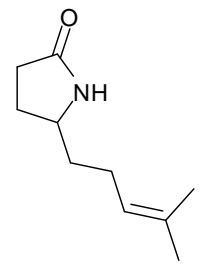

$26(47 \%)$

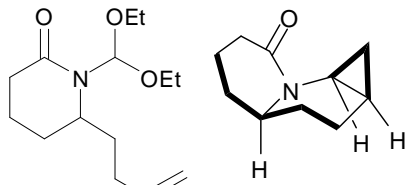

$10(42 \%) \quad 16(21 \%)^{\mathrm{c}}$

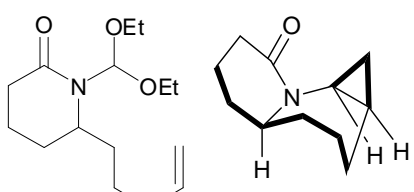

$11(55 \%) \quad 17(26 \%)^{\mathrm{c}}$
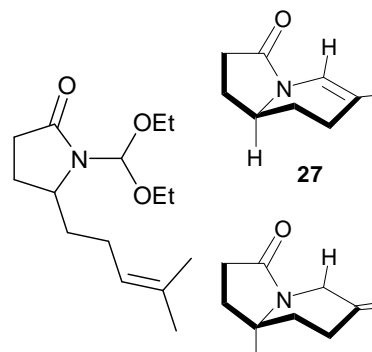

O

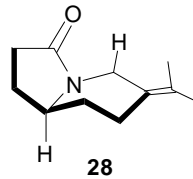

$12(66 \%) \quad$ not isolated

Table $1^{\mathrm{a}} \mathrm{Zn}(\mathrm{Hg}) ;{ }^{\mathrm{b}} \mathrm{Zn}$; ${ }^{\mathrm{c}} \mathrm{Zn} / \mathrm{CuCl}$

Examination of these results reveals that selection of a tethered $\gamma$-lactam derivative provided the highest yields (entries 2 and 3) irrespective of whether the organozinc carbenoid was participating in formation of a bicyclo [4.1.0] (six-membered ring) or a [5.1.0] (seven-membered ring) subunit. By way of contrast, the use of either the more conformationally mobile tethered $\delta$-lactams (entries 4 and 5) or of the relatively rigid $\beta$-lactam (entry 1) led to a significant reduction in yield. Moreover, the selection of a trisubstituted alkene tether as in substrate $\mathbf{1 2}$ (entry 6) furnished a mixture of the cyclic alkenes $\mathbf{2 7}$ and $\mathbf{2 8}$, as evidenced by NMR analysis of the crude reaction mixture, and no cyclopropane was detected. A possible mechanism for the formation of $\mathbf{2 7}$ and $\mathbf{2 8}$ is outlined in Scheme 4. 


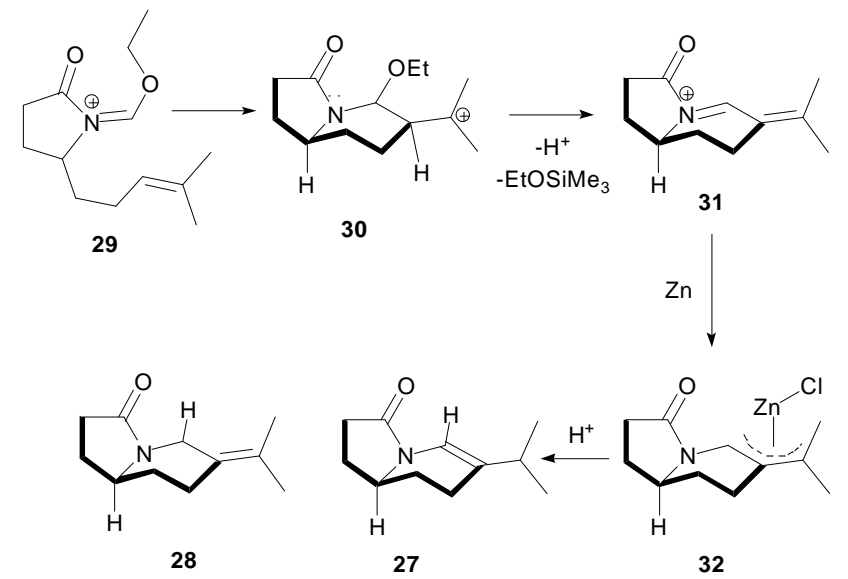

Scheme 4

Clearly, in this instance, cyclisation of the trisubstituted alkene onto the low energy $N$-acyl iminium cation 29 must be faster than two-electron reduction by zinc. Proton loss followed by Lewis acidmediated departure of the second ethoxy group then gives the conjugated acyl iminium ion 31, which can be reduced to give the allylzinc species 32. Protonation of $\mathbf{3 2}$ then gives a mixture of the two alkenes $\mathbf{2 7}$ and $\mathbf{2 8}$.

From a stereochemical standpoint, it was important to determine whether the cyclopropane unit was the more hindered endo isomer 14, as opposed to the sterically less congested exo diastereoisomer 33 (Table 2). Since these two isomers were not likely to be distinguishable using simple NMR techniques, a combined NMR calculation and molecular modelling approach was used to determine which structural isomer provided the best fit with the NMR data.

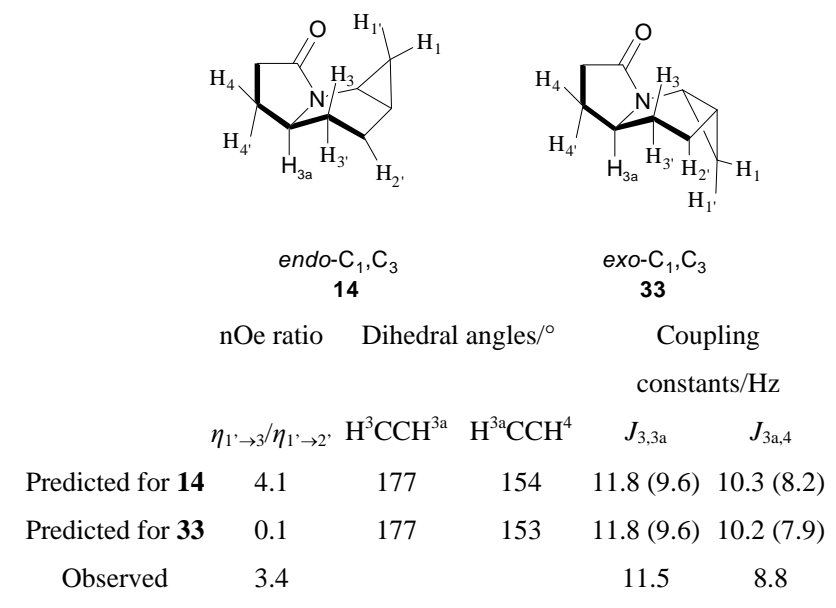

Table 2 Vicinal ${ }^{3} J_{\mathrm{HH}}$ couplings were predicted using a Karplus-type equation, ${ }^{17}$ accounting for the dependence of ${ }^{3} J_{\mathrm{HH}}$ on both the dihedral angle and the substituent electronegativities. The values shown in brackets are from the B3LYP/6-311+G(2d,p) calculations of the $J$ couplings 
Thus, the geometry of the predominant configuration and conformation for each polycylic compound was confirmed by a detailed comparison of the observed ${ }^{1} \mathrm{H}-{ }^{1} \mathrm{H}$ coupling constants and nuclear Overhauser enhancements (nOe) with values obtained from molecular mechanics calculations using the MMX force field ${ }^{18}$ followed by DFT calculations using the B3LYP/6-31G(d) level of theory. ${ }^{19}$ As an illustration, in the case of compounds $\mathbf{1 4}$ and $\mathbf{3 3}$ computational studies allowed prediction of the nOe ratios, dihedral angles, chemical shifts and coupling constants for both isomers as depicted in Table 2, showing two large ${ }^{3} J_{\mathrm{HH}}$ couplings on proton $3 \mathrm{a}-\mathrm{H}$. Comparison with the experimental results clearly indicated the endo-orientation of the $3-\mathrm{CH}_{2}$ and the cyclopropane ring (denoted as endo- $\mathrm{C}_{1}, \mathrm{C}_{3}$ ). In particular, on selective excitation of proton 1'-H the corresponding enhancement ratio for protons $3-\mathrm{H}$ and $2^{\prime}-\mathrm{H}\left(\eta_{1^{\prime} \rightarrow 3} / \eta_{1^{\prime} \rightarrow 2^{\prime}}\right)$ was found to be 3.4. From the B3LYP/6-31G(d) optimised geometry, the internuclear distances, $r$, between protons 1'-3 and 1 ' -2 ' in the endo- $\mathrm{C}_{1}, \mathrm{C}_{3}$ conformation are $2.44 \AA$ and $3.09 \AA$, respectively. Thus, using the initial rate approximation, ${ }^{20}$ which is based on the $r^{-6}$ dependence of nOe's, the expected enhancement ratio is 4.1. This compares well with the measured value of 3.4. For comparison, the expected nOe ratio is only 0.1 in the alternative exo- $\mathrm{C}_{1}, \mathrm{C}_{3}$ conformation (Table 2). A detailed discussion of this approach and further examples are provided in the supplementary information

The preference for formation of the more hindered product may possibly be rationalised by consideration of the two possible transition states shown in Figure 1, both of which feature an "amidoorganozinc carbenoid" in which the oxygen atom of the lactam is coordinated to the zinc atom. The observed stereochemical outcome would result from the less strained and less sterically congested approach of the alkene to the carbenoid $\mathbf{A}$, rather than the somewhat more hindered approach $\mathbf{B}$ which would lead to the exo isomer.

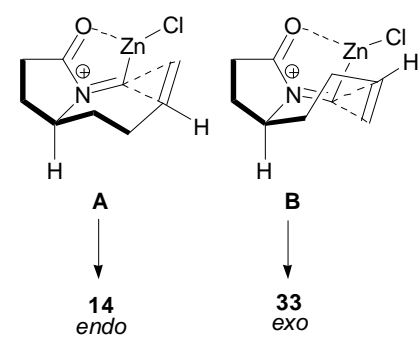

\section{Figure 1}

In summary, the results of this preliminary study clearly demonstrate that amidoorganozinc carbenoids derived from suitably constituted $N$-diethoxymethyl-lactams can successfully participate in intramolecular reactions with tethered monosubstituted alkenes. In all cases studied, only one diastereoisomer was isolated and the stereochemical preference is for formation of the cyclopropane 
on the more hindered concave face of the molecule. From an experimental standpoint, the overall sequence is inexpensive and the zinc/chlorotrimethylsilane-mediated cyclopropanation reaction occurs under mild conditions, thus paving the way for the construction of a range of usefully functionalised polycyclic amidocyclopropane systems.

\section{Acknowledgments}

We would like to thank the EPSRC for providing both a studentship (to LJ) and a postdoctoral fellowship (to TDS).

\section{References}

1. a) Saläun, J. Top. Curr. Chem. 2000, 207, 1; b) Saläun, J.; Baird, M. S. Curr. Med. Chem. 1995, 2, 511; c) Gnad, F.; Reiser, O. Chem. Rev. 2003, 103, 1603; d) Stammer, C. H. Tetrahedron 1990, 46, 2231; e) Burgess, K.; Ho, K. -K.; Moye-Sherman, D. Synlett 1994, 575.

2. a) King, S. W.; Riordan, J. M.; Holt, E. M.; Stammer, C. H. J. Org. Chem. 1982, 47, 3270; b) Aggarwal, V. K.; de Vicente, J.; Bonnert, R. V. Org. Lett. 2001, 3, 2785; c) Tsai, C. -C.; Hsieh, I. -L.; Cheng, T. -T.; Tsai, P. -K.; Lin, K. -W.; Yan, T. -H. Org. Lett. 2006, 8, 2261.

3. a) Vilsmaier, E. The Chemistry of the Cyclopropyl Group; Rappoport Z., Ed, John Wiley \& Sons: Chichester, 1987, 1341; b) Davies, H. M. L.; Cantrell Jr, W. R. Tetrahedron Lett. 1991, 32, 6509; c) Charette, A. B.; Cote, B. J. Am. Chem. Soc. 1995, 117, 12721; d) Davies, H. M. L; Bruzinski, P. R.; Lake, D. H.; Kong, N.; Fall, M. J. J. Am. Chem. Soc. 1996, 118, 6897.

4. Begis, G.; Cladingboel, D. E.; Motherwell, W. B. Chem. Commun. 2003, 2656.

5. Begis, G.; Sheppard, T. D.; Cladingboel, D. E.; Motherwell, W. B.; Tocher, D. A. Synthesis 2005, 3186.

6. a) Motherwell, W. B.; Bégis, G.; Cladingboel, D. E.; Jerome, L.; Sheppard, T. D. Tetrahedron 2007, 63, 6462; b) Bégis, G.; Cladingboel, D. E.; Jerome, L.; Motherwell, W. B.1 Sheppard, T. D. Eur. J. Org. Chem. 2009, 1532.

7. Zhao, C.; Zaho, Y.; Gong, P. Bioorg. Med. Chem. 2006, 14, 2552.

8. Brighty, K.E.; Castaldi, M. J. Synlett 1996, 1097.

9. Li, Q.; Wodds, K. W.; Clairbone, A.; Gwaltney, S. L., II; Barr, K. J.; Liu, G.; Gehrke, L.; Credo, R. B.; Hui, Y. H.; Lee, J.; Warner, R. B.; Kovar, P.; Nukkala, M. A.; Zielinski, N. A.; Tahir, S. K.; Fitzgerald, M.; Kim, K. H.; Marsh, K.; Frost, D.; Ng, S. C.; Rosenberg, S.; Sham, H. Bioorg. Med. Chem. Lett. 2002, 12, 465. 
10. a) Kulinkovich, O. G.; Sviridov, S. V.; Vasilevski, D. A.; Prityckaja, T. S. J. Org. Chem. (USSR) 1983, 25, 2027; b) Kulinkovich, O. G.; Sviridov, S. V., Vasilevski, D. A. Synthesis 1991, 234; c) Kulinkovich, O. G.; Kananovich, D. G. Eur. J. Org. Chem. 2007, 2121.

11. a) Chaplinski, V.; De Meijere, A. Angew. Chem. Int. Ed. Engl. 1996, 35, 413; b) de Meijere, A.; Kozhushkov, S. I.; Savchenko, A. I. J. Organomet. Chem. 2004, 689, 2033; c) de Meijere, A.; Williams, C. M.; Koudioukov, A.; Sviridov, S. V.; Chaplinski, V.; Kordes, M.; Savchenko, A. I.; Stratmann, C.; Noltemeyer, M. Chem. Eur. J. 2002, 8, 3789; d) Kulinkovich, O. G.; de Meijere, A. Chem. Rev. 2000, 100, 2789; e) Chaplinski, V.; Winsel, H.; Kordes, M.; de Meijere, A. Synlett 1997, 111.

12. For examples of intramolecular Ti-mediated aminocyclopropantion reactions see: a) Bertus, P.; Szymoniak J. Org. Lett. 2007, 9, 659; b) Gensini, M.; Kozhushkov, S. I; Yufit, D. S.; Howard, J. A. K.; Es-Sayed, M.; de Meijere, A. Eur. J. Org. Chem. 2002, 2499; c) Gensini, M.; de Meijere A. Chem. Eur. J. 2004, 10, 785; d) Larquetoux, L.; Ouhamou, N.; Chiaroni, A.; Six, Y. Eur. J. Org. Chem. 2005, 4654; e) Cao, B.; Xiao, D.; Jouillé, M. M. Org. Lett. 1999, 1799; f) Tebben, G.-D.; Rauch, K.; Stratmann, C.; Williams, C. M.; de Meijere, A. Org Lett. 2003, 5, 483; g) Ouhamou, N.; Six, Y. Org. Biomol. Chem. 2003, 1, 3007; h) Lee, H. B.; Sung, M. J.; Blackstock, S. C.; Cha, J. K. J. Am. Chem. Soc. 2001, 123, 11322; i) Laroche, C.; Bertus, P.; Szymoniak, J. Tetrahedron Lett. 2003, 44, 2485; j) Madelaine, C.; Ouhamou, N.; Chiaroni, A.; Vedrenne, E.; Grimaud, L.; Six, Y. Tetrahedron 2008, 64, 8878.

13. Jain, S. L.; Sain, B. J. Mol. Catal. A 2004, 212, 91.

14. Karstens, W. F. J.; Stol, M.; Rutjes, F. P. J. T.; Kooijman, H.; Spek, A. L.; Hiemstra, H. J. Organomet. Chem., 2001, 624, 244.

15. Bateson, J. H.; Baxter, A. J. G.; Roberts, P. M.; Smale, T. C.; Southgate, R. J. Chem. Soc., Perkin Trans. 1 1981, 3242.

16. Gmeimer, P.; Bollinger, B. Synthesis 1995, 168.

17. Haasnoot, C. A. G.; Deleeuw, F. A. A. M.; Altona, C. Tetrahedron, 1980, 36, 2783.

18. Schlecht, M. F. Molecular Modelling on the PC, Wiley-VCH, New York, 1998. Software used: PCMODEL (version 8.5, Serena Software).

19. Gaussian 03 Revision D.02, Frisch, M. J.; Trucks, G. W.; Schlegel, H. B., Scuseria, G. E.; Robb, M. A.; Cheeseman, J. R.; Montgomery Jr, J. A.; Vreven, T; Kudin, K. N.; Burant, J. C.; Millam, J. M.; Iyengar, S. S.; Tomasi, J.; Barone, V.; Mennucci, B.; Cossi, M.; Scalmani, G.; Rega, N.; Petersson, G. A.; Nakatsuji, H.; Hada, M.; Ehara, M.; Toyota, K.; Fukuda, R.; Hasegawa, J.; Ishida, M.; Nakajima, T.; Honda, Y.; Kitao, O.; Nakai, H.; Klene, M.; Li, X.; Knox, J. E.; Hratchian, H. P.; Cross, J. B.; Bakken, V.; Adamo, C.; Jaramillo, J.; Gomperts, R.; 
Stratmann, R. E.; Yazyev, O.; Austin, A. J.; Cammi, R.; Pomelli, C.; Ochterski, J. W.; Ayala, P. Y.; Morokuma, K.; Voth, G. A.; Salvador, P.; Dannenberg, J. J.;. Zakrzewski, V. G.; Dapprich, S.; Daniels, A. D.; Strain, M. C.; Farkas, O; Malick, D. K.; Rabuck, A. D.; Raghavachari, K.; Foresman, J. B.; Ortiz, J. V.; Cui, Q.; Baboul, A. G.; Clifford, S.; Cioslowski, J.; Stefanov, B. B.; Liu, G.; Liashenko, A.; Piskorz, P.; Komaromi, I.; Martin, R.L.; Fox, D. J.; Keith, T.; AlLaham, M. A.; Peng, C. Y.; Nanayakkara, A.; Challacombe, M.; Gill, P. M. W.; Johnson, B.; Chen, W; Wong, M. W.; Gonzalez, C;. Pople, J. A. Gaussian, Inc., Wallingford, CT, 2004.

20. Neuhaus, D.; Williamson, M. P; The Nuclear Overhauser Effect in Structural and Conformational Analysis, Wiley-VCH, 2nd ed., 2000. 